\title{
Pobres y pobreza en los testamentos (Reino de Chile, 1585-1641) ${ }^{*}$
}

\section{The poor and poverty in the testaments (Kingdom of Chile, 1585-1641)}

\author{
Pablo lacoste** \\ Instituto de Estudios Avanzados \\ Universidad de Santiago de Chile \\ Santiago \\ Chile
}

ENRIQUE CRUZ*** Consejo Nacional de Investigaciones Científicas y Técnicas S. S. de Jujuy (Jujuy) Argentina

Carolina polanco**** Instituto de Estudios Avanzados Universidad de Santiago de Chile Santiago Chile

* $\quad$ Artigo recebido em: 03/07/2013. Aprovado em: 20/03/2014. Proyecto Dicyt 0312294 LG (Universidad de Santiago de Chile). http://dx.doi.org/10.1590/S0104-87752014000300008

** Profesor Titular del Instituto de Estudios Avanzados de la Universidad de Santiago de Chile, Chile. Contato: pablo. lacoste@usach.cl.

*** Investigador del Consejo Nacional de Investigaciones Científicas (CONICET), Argentina. Contato: profecruz@ yahoo.com.ar

**** Ayudante de Investigación del Instituto de Estudios Avanzados de la Universidad de Santiago de Chile, Chile. Contato: pablo.lacoste@usach.cl. 
RESUMEN En el artículo se analiza a los pobres y la pobreza en testamentos de Santiago de Chile entre fines del siglo XVI y el primer tercio del XVII, a partir de un corpus documental de 300 testamentos. Se considera que el temor, las actitudes y las prácticas realizadas respecto a la pobreza y los pobres en este período, se relacionan con la muerte próxima y el juicio de Dios. Por eso es que los pobres aparecen como la oportunidad de practicar las enseñanzas cristianas, acumular méritos, y mejorar el futuro de las propias almas. El desafío consiste, entonces, en examinar los testamentos santiaguinos para identificar la presencia de los pobres y la pobreza, atendiendo a comprender el sentido de esos conceptos en la mentalidad de los testadores.

Palabras clave pobreza, testamentos, Chile

ABSTRACT In this article the poor and poverty are analyzed in testaments of Santiago de Chile between the end of the $16^{\text {th }}$ century and the first third of the $17^{\text {th }}$ century, based on a documentary corpus of 300 testaments. It is considered that fear, behaviour, and practices with regard to poverty and the poor in this period are related to death and the judgment of God. For that reason, the poor appear as the opportunity to teach Christian lessons, collecting merits, and improving the future of their own souls. Therefore, the challenge is to examine the testaments of Santiago in order to identify the presence of the poor and poverty, paying attention to understand the meaning of those concepts in the mentality of the testators.

Keywords poverty, testaments, Chile

Un tercio de la población de América Latina (180 millones de personas) se encuentra en la pobreza. ${ }^{1}$ El problema no es reciente; sus raíces ya eran visibles en el periodo colonial, cuando "los pobres constituían la gran mayoría de la población".?

El problema de los pobres y la pobreza en la región es un tema de singular interés, en torno al cual se han realizado algunos avances, pero todavía en forma insuficiente. Es importante destacar que la mayor parte de los estudios de los sectores subalternos en el periodo colonial, se han decantado por la situación de los esclavos y los pueblos originarios; en cambio, la situación de los pobres ha merecido un interés menor de la aca-

1 COMISIÓN ECONÓMICA PARA AMÉRICA LATINA (CEPAL). Panorama social de América Latina 2010. Santiago de Chile: Libros de la Cepal, 2010.

2 VILLALOBOS, Sergio. Historia del pueblo chileno. t.IV, siglo XVII, Santiago: Editorial Universitaria, 2000, p.280. 
demia. De todos modos, en los últimos años también se ha comenzado a cultivar este campo con estudios sobre los pobres como una "clase social" relevante en las urbes coloniales". ${ }^{3}$ La calificación "clasista" de la pobreza en el Antiguo Régimen Indiano de parte de algunos trabajos históricos, tiene en cuenta la idea de que la pobreza genera una conciencia a partir del enfrentamiento con los poderosos, planteando que los pobres eran las personas que carecían de lo necesario para subsistir o que subsistían sin comercio o especial adiestramiento, viviendo llenos de incertidumbre social, con sensación de miedo, alienación y resentimiento. ${ }^{4}$

La consideración social y económica de la pobreza en el Occidente Europeo es otro rasgo de los estudios históricos sobre el Orbe Indiano. Así se ha estudiado la pobreza y la mendicidad a fines de la colonia en el contexto de las reformas borbónicas en la capital de la capitanía general de Venezuela, relacionándola con la pauperización desarrollada en Europa entre los siglos XVII y XVIII. ${ }^{5}$ De manera similar para el virreinato de Nueva España, se ha aplicado el concepto de pobreza medieval al estudio del "beneficio de pobreza". ${ }^{6}$ En síntesis, a estos estudios se suman otros regionales para México, ${ }^{7}$ Ecuador, ${ }^{8}$ Chile, ${ }^{9}$ y Argentina.${ }^{10}$ Con los cuales el presente artículo se propone examinar los pobres y la pobreza a partir de una fuente muy precisa: los testamentos. Se estudian allí tanto el aporte de los testadores a las entidades dedicadas a los pobres, como las declaraciones de pobreza y su sentido. El corpus documental se ha formado con 300 testamentos protocolizados en Santiago de Chile entre 1585 y 1637.

Los testamentos como fuentes históricas, han sido considerados como mecanismos de regulación y control social, como una inmensa red ideológica que se echaba sobre la realidad para amoldarla según los criterios

3 HASLIP-VIERA, Gabriel. La clase baja. In: HOBERMAN, Louise; SOCOLOW, Susan (comp.). Ciudades y sociedad en Latinoamérica Colonial. México: Fondo de Cultura Económica, 1993, p.331-364.

4 MALLO, Silvia. Pobreza y formas de subsistencia en el virreinato del Río de la Plata a fines del siglo XVIII. EstudiosInvestigaciones, La Plata, n.1, p.46, 1989.

5 LANGUE, Frédérique. Desterrar el vicio y serenar las conciencias: mendicidad y pobreza en la Caracas del siglo XVIII. Revista de Indias, Madrid, LIV: 201, p.380-381, 1994.

6 ABADIE-AICARDI, Aníbal. Contexto socio-cultural de la condición de pobreza y el beneficio de pobreza en la Universidad de México (1553- 1700). Jahrbuch fur Gerschichte Lateiamerikas, Colonia, n.33, p.99-128, 1996.

7 ARROM, Silvia Marina. Containing the poor: the Mexico City Poorhouse, 1774-1871. Durham: Duke University Press, 2000.

8 MILTON, Cynthia. The many meanings of poverty: colonialism, social compacts and assistance in Eighteenth-Century Ecuador. Stanford: Stanford University Press, 2007

9 CAVIERES, Eduardo. Sociedad rural y marginalidad social en el Chile tradicional, 1750-1860. In: IZQUIERDO, Gonzalo (ed.). Agricultura, trabajo y sociedad en América Hispana. Santiago: Universidad de Chile/USACH/UCV/ UMCE/Embajada de España en Chile, 1989, p.91-105; VILLALOBOS, Sergio. Historia del pueblo chileno; LEÓN, Leonardo. Ni patriotas ni realistas: el bajo pueblo durante la independencia de Chile (1810-1822). Santiago: Centro Diego Barros Arana, 2012. LEÓN LEÓN, Marco Antonio. Muerte y buena muerte en Chile colonial. In: SÁNCHEZ GAETE, Marcial (dir.). Historia de la Iglesia en Chile: En los caminos de la conquista espiritual. t.1, Santiago: Editorial Universitaria, 2009, p.193-230; PONCE DE LEÓN ATRIA, Macarena. Gobernar la pobreza: prácticas de caridad y beneficencia en la ciudad de Santiago, 1830-1890. Santiago: Editorial Universitaria/Dibam, 2011.

10 MALLO, Silvia. Pobreza y formas de subsistencia en el virreinato del Río de la Plata a fines del siglo XVIII; CRUZ, Enrique Normando. Auxiliando a los pobres de balde: la profesión médica en el Jujuy colonial. Colonial Latin American Historical Review, New Mexico, v.11, p.153-176, 2002. 
de los grupos dominantes. ${ }^{11}$ Por eso es que a través de ellos podemos conocer algunos de los preceptos religiosos de la sociedad iberoamericana, empapados en los valores cristianos pre y postridentinos, que exhortaban a toda la comunidad a socorrer a los pobres. En el marco de una sociedad oficialmente católica, la caridad era reconocida como virtud teologal; y en el centro de la doctrina estaban las enseñanzas evangélicas de "ama a tu prójimo como a tí mismo" (Mc 12: 29-31) y "Amaos los unos a los otros como yo los he amado" (Jn 13,34). La gloria eterna estaba prometida para aquellos que expresaran su amor a Dios, precisamente, a través de la acción de solidaridad hacia los pobres (Mt 25: 31-40).

En el ámbito específico del periodo colonial, el desafío es tratar de comprender quiénes eran los pobres, cuáles fueron sus vínculos con el poder, y las posibilidades y uso que se le dio a la pobreza como estrategia de adaptación. Por un lado, ya se ha comenzado a examinar la particular forma de vinculación de los pobres con la justicia. ${ }^{12}$ Despojados de privilegios, los pobres debían soportar la injusticia de ver que, por iguales delitos, las penas eran diametralmente distintas si el responsable era noble (y detentaba fueros y privilegios) o si era pobre. La pobreza no era solo una situación de escasez de bienes; no era una condición objetiva, sino subjetiva, es decir, relativa a la situación social de la persona; de allí la diferencia entre "pobreza solemne" y "pobreza vergonzante". ${ }^{13}$

El presente artículo se propone examinar los pobres y la pobreza en testamentos de Santiago de Chile entre fines del siglo XVI y el primer tercio del XVII, a partir de un corpus documental de 300 testamentos. Se trata de profundizar el trabajo de Luis Alberto Romero, ${ }^{14}$ con algunas variaciones. Por un lado, tenemos una diferencia temporal (Romero examina un periodo posterior, situado en el siglo XIX); también tenemos fuentes distintas: dicho autor examina el problema desde la mirada de las élites, a partir de fuentes literarias, mostrando la imagen que los grupos dominantes elaboraron sobre los pobres. En cambio, este trabajo examina fuentes primarias en las cuales se incluyen distintas voces: aparecen hacendados con actitudes de caridad hacia los pobres, juntamente con testadores que se reconocen pobres a sí mismos como parte de una estrategia material y moral para obtener un beneficio eclesiástico o socioeconómico. Por otra parte, la fuente presenta también una diferencia de enfoque: en ambos casos, se escribe desde el miedo, pero en un sentido distinto. Las elites del Santiago de la segunda

11 SANTA CRUZ, Lucía Invernizzi. El testamento como instrumento de regulación y control de la sociedad chilena del siglo XVII. In: RETAMAL, Julio (coord.). Estudios Coloniales II. Santiago: Universidad Andrés Bello, 2002, p.193-206.

12 FERNÁNDEZ, Marcos. El hombre pobre frente al perdón y la justicia. In: RETAMAL, Julio (coord.). Estudios Coloniales II. Santiago: Universidad Andrés Bello, 2002, p.195-212.

13 CRUZ, Enrique Normando. Pobreza, pobres y política social en el Río de la Plata. Boletín del Instituto de Historia Argentina y Americana "Dr. Emilio Ravignani", Buenos Aires, n.30, p.101-117, 2007

14 ROMERO, Luis Alberto. ¿Qué hacer con los pobres? Elite y sectores populares en. Santiago de Chile, 1840-1895. Buenos Aires: Sudamericana, 1997. 
mitad del siglo XIX contemplan el crecimiento de la población en general y de las masas de pobres en particular, como una amenaza, en el marco de la emergente "cuestión social" moderna. En cambio, los testadores del 1600 tienen sus temores focalizados en la muerte próxima y el juicio de Dios propios del Antiguo Régimen. Ellos no le temen a los pobres sino, al contrario: los pobres aparecen como una oportunidad de practicar las enseñanzas cristianas, acumular méritos y mejorar el futuro de sus almas. Mientras que para las élites secularizadas modernas los pobres eran fuente de temor, para los testadores de 300 años antes eran una oportunidad.

\section{El hospital como principal medio de solidaridad del testador con los pobres}

Los hospitales fueron parte esencial de la política social de España en sus reinos de las Indias. A mediados del siglo XVI, la Corona dispuso que todas las ciudades debían tener hospitales para atender a los enfermos y confortar a los pobres. Los hospitales quedaban a cargo de un mayordomo, encargado de la administración, y debían contratar a un médico para atender a los enfermos. También solían tener su propia iglesia y un cementerio. Para conformar el presupuesto, se estableció que debía destinarse a este fin un noveno y medio de los ingresos en concepto de diezmos. ${ }^{15}$ Como los fondos del hospital dependían de la recaudación, y esta a su vez del nivel de actividad económica, en los pequeños pueblos, más que servicios de salud, era una casa en la cual se entregaba limosna a los pobres. ${ }^{16}$

En la expansión de las redes de hospitales por América Latina, un papel destacado cupo a los órdenes religiosas hospitalarias, particularmente la de San Juan de Dios y la de los Betlemitas, fundadas respectivamente en España (siglo XVI) y en Guatemala (siglo XVII). A partir del hospital de Granada fundado en 1550 por San Juan de Dios, se produjo una fuerte expansión de esta experiencia, primero en España, y luego en toda América Latina. Los religiosos de San Juan de Dios y los betlemitas extendieron sus servicios por toda la región, fundando y atendiendo hospitales de México hacia el sur, pasando por Cuba y Perú, hasta llegar a Chile y el Río de la Plata. ${ }^{17}$ Dentro del reino de Chile la orden de San Juan quedó a cargo del hospital de Santiago, donde levantaron su propia iglesia y el cementerio. ${ }^{18}$ Los betlemitas intentaron fundar el segundo hospital en la capital y obtuvieron

15 AGUIRRE MEDRANO, Fidel. Historia de los hospitales coloniales en Hispanoamérica, siglo XVI- XIX. v.I-VIII, Caracas: Editorial Arenas, 1992.

16 Similar fue la función y tarea de los hospitales de los reinos españoles de la Península lbérica. LÓPEZ ALONSO, Carmen. La pobreza en la España Medieval: estudio histórico-social. Madrid: Centro de Publicaciones del Ministerio de Trabajo y Seguridad Social, 1986.

17 MAYO, Carlos. Los betlemitas en Buenos Aires: convento, economía y sociedad (1748-1822). Sevilla: Diputación Provincial de Sevilla y Junta de Andalucía, 1991.

18 LEÓN LEÓN, Marco Antonio. Muerte y buena muerte en Chile colonial, p.201. 
cierto respaldo del rey (Real Cédula de 1734). Pero entraron en conflicto con el obispo quien informó al rey que "tal religión no se necesita en esta ciudad ni cabe en ella". ${ }^{19}$ Buscaron otros horizontes y hacia 1763 se instalaron en Mendoza, donde lograron levantar el primer hospital en 1790..$^{20}$

En el Reino de Chile el primer hospital fue el de Santiago, fundado en 1552. Posteriormente se levantaron los nosocomios de Concepción, Valparaíso, Villarrica, Chillán (1791) y otras ciudades. En la primera mitad del siglo XVII, el hospital "San Juan de Dios", de Santiago, contaba con construcciones específicamente sanitarias, juntamente con la infraestructura para los religiosos que lo atendían (habitaciones, refectorio, iglesia), y sus propios medios de subsistencia (terreno cercado de tapia, plantado de viñas, con trojes, despensas y amasijo). Destruido por el terremoto de 1647, fue nuevamente construido; un siglo después con sus 104 capas y dos pabellones (para mujeres y hombres separados), se estimaba el valor del hospital en cerca de $\$ 10.000$. Poco después se tomó la decisión de crear un segundo hospital, para aprovechar los edificios de novicios de los jesuitas expulsos. ${ }^{21}$ Paralelamente, en Valparaíso, se acordó entregar la sede del Colegio jesuita al hospital de esta ciudad, a cargo de los religiosos de San Juan de Dios. ${ }^{22}$

Lo primero que reflejan los testamentos de Santiago de Chile, es que la acción de solidaridad de los testadores se canalizó principalmente a través de donaciones al hospital. De los 300 testamentos registrados, las donaciones para pobres se detectaron en 14 casos; siendo el objetivo de 12 donaciones los bienes destinados a "los pobres del hospital" o al "hospital de los pobres".

El Hospital de los Pobres "Nuestra Señora del Socorro" se fundó tempranamente, durante el gobierno de Pedro de Valdivia. Según lo dispuso el Cabildo de Santiago, casi una década después de la fundación de la ciudad (1552), fue emplazado en la Cañada de San Francisco, sobre el costado sur. El Hospital era administrado por el Mayordomo, el cual era designado por el gobernador de Chile de una terna propuesta por el obispo de Santiago, todo ello con arreglo a las normas establecidas por la Corona y de acuerdo a la práctica colonial de designar un miembro conspicuo del patriciado local para desempeñar un oficio que atañía a una de las principales responsabilidades del gobierno colonial: la atención de la pobreza y los pobres. ${ }^{23}$

19 TORIBIO MEDINA, José. Cosas de la colonia: apuntes para la crónica del siglo XVIII en Chile. Introducción de Eugenio Pereira Salas. Santiago: Fondo Histórico y Bibliográfico José Toribio Medina, 1952, p.440.

20 PONTE, Ricardo. De los caciques del agua a la Mendoza de las acequias. Mendoza: Incihusa, 2005, p.27-28.

21 DE RAMÓN, Armando. Santiago de Chile 1541-1991. Santiago: Editorial Sudamericana, 2000, p.113-114.

22 TORIBIO MEDINA, José. Cosas de la colonia, p.375.

23 La condición jurídica de "miserabilis" y la relación social de la "pobreza", son dos aspectos que legitimaron el gobierno real Austria en los reinos europeos e indianos. CASTAÑEDA DELGADO, Paulino. La condición miserable del indio y sus privilegios. Anuario de Estudios Americanos, Sevilla, v.28, p.245-272, 1971. 
En la temprana fecha de 1603 se nombró en ese cargo a fray Juan Pérez de Espinoza, con un salario anual de $\$ 200$, mitad en metálico y mitad en especie (harina, leña, vino y carneros). ${ }^{24}$ Evidentemente, las autoridades esperaban contar con un importante flujo de recursos para al hospital, según se desprende de los emolumentos que recibiría el Mayordomo. No obstante, las expectativas se vieron frustradas. Un año después, se procedió a buscar nuevas autoridades, pero sin sueldo. En efecto, el 27 de agosto de 1604 se nombró a Luis de la Torre Mimeza y Juan Guerra como mayordomo y cirujano respectivamente. ${ }^{25}$ También sirvió como mayordomo sin sueldo en el hospital el capitán Alonso del Campo Lantadilla, el cual procuró aportar el trabajo de sus esclavos y recursos personales. En 1607 denunció que el edificio se hallaba en ruinas y era incapaz de atender a todos los enfermos, tanto españoles como indígenas. ${ }^{26}$ Poco después, el nosocomio se menciona como "Hospital Real" y estaba administrado por los padres hospitalarios de San Juan. Las penurias económicas seguían presentes y los salarios se pagaban con atraso. En 1640 falleció el padre Pedro Ladrón de Leiva, cura y vicario del Hospital, al cual se le adeudaban $\$ 116$ de salarios atrasados. ${ }^{27}$

Mientras las elites patricias podían pagar los servicios del médico particular, los pobres quedaban sujetos al servicio que podían conseguir en el hospital, que se hallaba en esas precarias condiciones. El Estado del Antiguo Régimen no incluía el cuidado de la salud púbica entre sus funciones específicas. Por lo tanto, los recursos dedicados al hospital dependían principalmente de la caridad. De allí la importancia del aporte que pudieran realizar los testadores.

Las donaciones de testadores en favor del hospital podían ser en dinero o en especie. Los aportes en especie fueron de tres tipos: para el culto (velas, imaginería); objetos de uso (ropa, muebles) y trabajo de esclavos. En efecto, Andrés Torquemada (1590) donó un lustro de trabajo de sus dos esclavas. ${ }^{28}$ Así lo señaló en su codicilo:

Quiere y es su voluntad que atento que una cláusula de su testamento mando que Catalina, Juana y María sus esclavos hijas de la dicha Catalina sirviesen al Hospital de pobres de esta ciudad çierta cantidad de años como se contiene por la cláusula de testamento que el dicho tiempo se entienda y sea no mas que

24 AMUNÁTEGUI, Domingo. La sociedad de Santiago en el siglo XVII. Santiago de Chile: Dirección General de Prisiones, 1937, p.68-69.

25 AMUNÁTEGUI, Domingo. La sociedad de Santiago en el siglo XVII, p.82.

26 AMUNÁTEGUI, Domingo. La sociedad de Santiago en el siglo XVII, p.121.

27 Poder para testar del padre Pedro Ladrón de Leiva, Santiago, 7 de febrero de 1640. Archivo Nacional (en adelante AN), Fondo Escribanos de Santiago (en adelante FES), volumen 186, folio 309.

28 La donación de esclavos para el servicio en los hospitales era una práctica común en los establecimientos para pobres del Río de la Plata. MAYO, Carlos. Los betlemitas en Buenos Aires. Y también en la Audiencia de Charcas. CALVO VERA, Alfredo. Orígenes de la asistencia social, hospital de indios de Potosí, siglo XVI. Anuario del Archivo y Biblioteca Nacionales de Bolivia, Sucre, p.461-467, 1999. CHACÓN TORRES, Mario. Los hospitales del Potosí Virreinal. Historia y Cultura, La Paz, v.10, p.29-57, 1986. 
seis años y, cumplidos queden las susodichas libres y sus hijos para que hagan de si lo que quisieren como personas libres. ${ }^{29}$

Más frecuente eran las donaciones al Hospital de pobres en valores expresados en dinero. Según el monto aportado, se pueden clasificar los donantes en tres niveles: bajo (entre $\$ 1$ y $5 \$$ ), medio (de $\$ 10$ a $\$ 50$ ), o alto (\$100 o más) (Tabla 1).

\section{Tabla 1}

Donaciones al Hospital de Santiago en los testamentos (Santiago de Chile, 1585-1641)

\begin{tabular}{|c|c|c|c|}
\hline DONANTE & AÑO & MONTO & Nivel \\
\hline Melchor de Ecija & 1585 & $\$ 20$ & Medio \\
\hline Antogno de Fericho & 1586 & $\$ 16$ & Medio \\
\hline Antonio Guzmán & 1587 & $\$ 10$ & Medio \\
\hline Luis Tenorio & 1587 & \$20 y mi cama y un solar en San Juan & Medio \\
\hline Diego Serrano & 1588 & $\$ 5$ & Bajo \\
\hline Juan Benítez de Escobar & 1588 & $\$ 4$ & Bajo \\
\hline Francisco Gutiérrez (pbro) & 1589 & Universales herederos & Alto \\
\hline Gaspar Sánchez & 1589 & $\$ 30$ & Medio \\
\hline Andrés de Torquemada & 1590 & $\$ 25$ & Medio \\
\hline Andrés de Torquemada & 1590 & 3 esclavos $\times 6$ años & Medio \\
\hline Isabel Núñez de Herrera & 1590 & $\$ 10$ y $\$ 24$ al Hospital de Villarrica & Medio \\
\hline Luisa Ortiz de Susunaga & 1591 & $\$ 1$ & Bajo \\
\hline Petronila Osorio & 1593 & $\$ 4$ & bajo \\
\hline Agueda Flores & 1595 & $\$ 50$ & Medio \\
\hline Juan Hurtado & 1595 & $\$ 246$ & Alto \\
\hline Mariana de Frías & 1595 & $\$ 4$ & Bajo \\
\hline Francisca Vargas & 1597 & $\$ 2$ (1 libra de cera)* & Bajo \\
\hline Juan Griego & 1636 & $\$ 20$ (en ropa) & Medio \\
\hline Juan García Salguero & 1636 & $\$ 100$ & Alto \\
\hline Lucía Pastén y Estrada & 1637 & $\$ 50$ (p/ imagen de San Juan de Dios) & Medio \\
\hline Antonio Jiménez Mazuelas & 1638 & $\$ 350$ & Alto \\
\hline Beatriz Ahumada & 1641 & $\$ 12(6$ libras cera) & Bajo \\
\hline
\end{tabular}

Fuente: Archivo Nacional, Fondo Escribanos de Santiago, 1585-1641.

* La valuación del precio de cada libra de cera es estimada, teniendo en cuenta los datos entregados por Muñoz (1992: 138). Sobre la base de estos antecedentes, para el presente cuadro se ha considerado un valor estimado de $\$ 2$ por libra.

La tendencia más difundida era el donante de nivel bajo (\$1 a \$5), y medio (\$10 a \$50). Los donantes de alto nivel eran casos excepcionales. Las donaciones de nivel bajo fueron seis (30\%), las de nivel medio llegaron 
a once (55\%) y las de nivel alto apenas tres (15\%). Entre los donantes bajos y medios concentraban el $85 \%$ de los casos. A su vez, los fondos que se donaban al hospital de los pobres eran una parte ínfima de los bienes dejados para ceremonias religiosas (misas, capellanías, limosnas para conventos y cofradías).

Desde la perspectiva de la religión católica, después de la muerte, el alma de las personas iba al Purgatorio (salvo los santos que iban directamente al cielo, y los condenados, que pasaban al infierno), el lugar donde se padecían tormentos similares a los del infierno, con la diferencia de ser temporales y no eternos. Para amortiguar el impacto de esa experiencia, la Iglesia ofrecía como soluciones las indulgencias y las misas. En el Orbe Indiano el mecanismo más difundido fue la misa, financiada a través de capellanías. ${ }^{30}$ La exitosa campaña realizada por el clero en el sentido de la gravedad de los tormentos del purgatorio y la eficiencia de la misa como mecanismo para eludirlos, fue la clave del alto nivel de inversión de rentas en capellanías y obras pías. Veamos algunos ejemplos.

Isabel Núñez de Herrera (1590) entregó \$10 al hospital de Santiago y \$24 al hospital de Villarrica, donde residía su marido. A su vez, para conventos (el de Villarrica y los conventos de San Francisco y de Monjas de Santiago), para la cofradía de la Inmaculada y para capellanías, destinó \$1810. Los fondos dedicados a los dos hospitales apenas representaban el 1,84\% de lo destinado a ritos religiosos. ${ }^{31}$

La actitud de entregar al hospital una cifra claramente inferior que la dedicada a ceremonias, ritos y conventos era la tendencia dominante en la época. Los casos de Melchor de Ecija (1585), que donó \$20 a los pobres del hospital y más de $\$ 151$ al culto, ${ }^{32}$ de Águeda Flores (1595), que donó al hospital $\$ 50$ y más de $\$ 330$ para misas y conventos, ${ }^{33}$ son también buenos ejemplos.

La supremacía del culto sobre la caridad y la beneficencia se reflejó también en el testamento de Andrés Torquemada (1590). Los \$25 que allí se preveían fuesen destinados al Hospital de los pobres, no eran un aporte directo, sino la opción última en caso de no lograrse el objetivo principal. Esos recursos correspondían a la renta anual por una capellanía que Torquemada fundó con un capital de $\$ 500$. El beneficiario directo y vitalicio de esa renta

30 LEVAGGI, Abelardo. Las capellanías en Argentina: estudio histórico-jurídico. Buenos Aires: Instituto de Investigaciones Jurídicas y Sociales "Ambrosio L. Gioja", 1992; MARTíNEZ LÓPEZ-CANO, María del Pilar, et al. Cofradías, capellanías y obras pías en América Colonial. México: Universidad Nacional Autónoma de México, 1998; SÁNCHEZ GAETE, Marcial. Reciprocidad entre vivos y muertos: la capellanía, un testigo de fe. In: Historia de la Iglesia en Chile: en los caminos de la conquista espiritual. t.1, Santiago: Editorial Universitaria, 2009, p.233-256.

31 Testamento de Isabel Núñez de Herrera, Santiago, 10 de mayo de 1590. AN, Escribanos de Santiago, volumen 5, folio 207. Este testamento tuvo otras peculiaridades: entre ellas, se destinaron \$24 al Hospital de Villarrica, que poco después fue destruido por el levantamiento general de los mapuches; también destinó cifras importantes para distribuir bienes entre los indios de su encomienda.

32 Testamento de Melchor de Ecija, Santiago, 20 octubre 1585. AN, Notariales de Santiago, volumen 3, folios 30v-32v.

33 Testamento de Águeda Flores, Santiago, 19 de mayo de 1595. AN, Escribanos de Santiago, volumen 9, folio 200. 
era el padre Juan Vara, siempre y cuando no perdiera su condición sacerdotal por cometer delito. El testamento preveía el destino de esas rentas, aún después de la muerte del beneficiario. Estipulaba una serie de condiciones, en las cuales se involucraba a otros clérigos y autoridades eclesiásticas. Y como último recurso, en caso de no lograrse orientar los recursos en forma adecuada, se establecía una cláusula por la cual se debían donar al hospital. El documento señalaba que: "si se pasare un año sin beneficiar la dicha capellanía por el tal caso la renta de la dicha capellanía del dicho año lo haya y goce el Hospital de los pobres de esta ciudad y su mayordomo los cobre y los pierda el dicho obispo, deán y cabildo y capellán". ${ }^{34}$

La donación de fondos a los pobres del hospital funcionó también como mecanismo de devolución de dinero que no pertenecía al testador sino a un tercero. La apropiación de ese dinero indebido generaba una tensión ética en un nuevo y creciente contexto mercantil, ${ }^{35}$ que se podía soportar durante un tiempo; pero ante la proximidad de la muerte, era necesario resolver el problema y aliviar la tensión, para enfrentar en paz el juicio de Dios. El caso de Gaspar Sánchez resulta esclarecedor al respecto. En su codicilo (1589), se afirma que

él es deudor a un marinero que se ahogó en el puerto de Chile que no sabe de dónde es natural ni como se llama hasta $\$ 150$ pesos de a ocho Reales el peso. Que su voluntad es que de los dichos sus bienes tomen sus albaceas la dicha cuantía y la distribuyan en esta manera: $\$ 30$ al Hospital de los pobres de esta ciudad y $\$ 20$ al monasterio de las monjas y los $\$ 100$ restantes los tres monasterios San Francisco, Santo Domingo, Nuestra Señora de la Merced y en la iglesia mayor de esta ciudad para que se les den a cada uno $\$ 25$ de la dicha plata o su valor oro para que lo digan de misas por el ánima del tal difunto a quien soy en obligación. ${ }^{36}$

El documento permite confirmar el patrón general. Se entregaban algunos recursos a los pobres del Hospital, pero siempre en un nivel inferior del que se dedicaba a salvar el alma mediante misas y ceremonias religiosas. Además, la donación no provenía de los propios bienes del donante, sino como forma de hacer justicia con bienes de un tercero o bien el reconocimiento póstumo y velado a una mala práctica comercial. Este tipo de situ-

34 Codicilo de Andrés Torquemada, Santiago, 17 de diciembre de 1590. AN, Escribanos de Santiago, volumen 6, folio 161.

35 El contexto de esta situación era el problema de la usura, que hasta el siglo XVIII será considerado como un dilema ético y religioso, el usurero es "un ladrón solapado en la opinión de los doctos de la Sorbona en 1731. No hay justificación para el usurero. Es mucho peor que el simple comerciante, porque como se expresa San Agustín es posible ejercer el comercio de un modo inocente sin faltar la Ley de Dios. El préstamo a interés es vicioso en sí mismo. La condena a la usura viene de que nadie debe sacar provecho sino de lo que le pertenece". GROETHUYSEN, Bernhard. La formación de la conciencia burguesa en Francia durante el siglo XVIII. México: Fondo de Cultura Económica, 1985, p.378-389.

36 Codicilo de Gaspar Sánchez, Santiago, 14 de marzo de 1589. AN, Escribanos de Santiago, volumen 4, folios 316-316v. 
aciones se verificó también en otro caso. El genovés Antogno de Fericcio, también incluyó a los pobres del Hospital en su testamento. En su última voluntad dispuso que "mando que se le dé al Hospital de esta ciudad y pobres de él $\$ 16$ de oro de cierta restitución que debo a personas inciertas". ${ }^{37}$

\section{Los grandes donantes y su perfil}

Las donaciones grandes de testadores al Hospital de pobres (Juan Hurtado, Juan García Salguero y Francisco Gutiérrez) fueron casos excepcionales pero interesantes. Como se ha señalado, de un total de 300 testamentos revisados, sólo se registraron tres donantes grandes. Se trata de situaciones excepcionales pero relevantes: el aporte de uno solo de estos donantes de nivel alto, Juan Hurtado, casi equivalía a la sumatoria de los aportes de todos los demás donantes de nivel bajo y medio, juntos. En efecto, los 17 donantes de esos grupos reunieron en total \$285, quedando apenas por encima de los \$246 que aportó Hurtado. ¿Quién era este sujeto? ¿Por qué hizo esa donación?

El perfil de Juan Hurtado corresponde a un miembro de los sectores altos de la administración española. Era contador de la Real Hacienda en el Reino de Chile. Ejercía por lo tanto, un puesto relevante que le aportaba influencia de tipo social, económica y política. El ejercicio de este oficio y la posesión del cargo le conferían un capital social considerable, al colocarlo en el centro de las redes de influencia en la región. Gozó de una posición prominente en la sociedad chilena, con amplias atribuciones y posibilidades. Al cerrar el ciclo de vida y para prepararse al buen morir, Juan Hurtado procuró darle a la sociedad parte de sus bienes. Al elaborar su testamento, Hurtado realizó una donación "al hospital de los pobres de esta ciudad por descargo de mi conciencia \$200 de oro de contado". ${ }^{38}$ A ello sumó otros aportes de rentas y derechos que el contador traspasó en propiedad y derecho al citado establecimiento:

Y mas doy al dicho hospital una obligación contra Pedro de Armenta que me debe 42 pesos y 6 tomines de oro de contrato de los cuales y del dicho censo hago renunciación y cedo y traspaso al dicho Hospital y a su mayordomo; y más le doy al dicho Hospital un peto y espaldar y una celada; mando se entregue al mayordomo del dicho hospital las dichas armas y las dichas escrituras. ${ }^{39}$

De esta manera se redondeaban las donaciones del Contador Juan Hurtado al hospital de los pobres, con $\$ 200$ en oro y $\$ 46$ en derechos para

37 Testamento de Antogno de Fericcio. Santiago, 2 de junio de 1586. AN, Escribanos de Santiago, volumen 3, foja 176

38 Testamento de Juan Hurtado, Santiago, 11 de septiembre de 1595. AN, Escribanos de Santiago, volumen 9, folios 257v

39 Testamento de Juan Hurtado, Santiago, 11 de septiembre de 1595. AN, Escribanos de Santiago, volumen 9, folios $257 v-258$. 
cobrar antiguas deudas; de esta manera, el funcionario real procuraba descargar su conciencia y morir en paz. En una posición cercana se encuentra el caso de Francisco Gutiérrez, el cual se ha incluido también en la categoría de los donantes de nivel alto; ello no se debe al valor exacto de la limosna, el cual no se ha podido identificar con claridad, sino a su valor relativo dentro de los bienes del testador. El aporte de Gutiérrez fue relativamente mayor al de Juan Hurtado, porque no dejó una parte sino la totalidad de sus bienes a los pobres del hospital, al nombrarlos como universales herederos: "Dejo y nombro por mis universales herederos a los pobres del Hospital de la parte y lugar donde yo muriere y si Dios nuestro señor fuere servido que yo muera fuera de esta ciudad todos los bienes que en ella hubiere o que me hayan de venir a ella los hereden los pobres del Hospital de esta ciudad". ${ }^{40}$

La decisión de Francisco Gutiérrez, en el sentido de nombrar a los pobres del hospital como sus universales herederos representa un caso excepcional en las testamentarías examinadas. Por lo general, los testadores reconocían como herederos a sus familiares; en algunos casos, sobre todo cuando no había herederos legítimos, se podía nombrar como heredera a "mi alma", de modo tal de transferir los bienes al sector eclesiástico para celebración de misas por el alma del difunto; era una inversión a largo plazo, para ayudarla a salir pronto del purgatorio y llegar cuanto antes de gozar de la presencia de Dios en el cielo. Los testamentos coloniales tienen muchos casos de este tipo, en todas las colonias hispanoamericanas. ${ }^{41} \mathrm{Sin}$ embargo, Francisco Gutiérrez eligió otro camino.

¿Quién era Gutiérrez? ¿Quien tuvo la actitud de, ignorando las recomendaciones que insistentemente reiteraban los clérigos desde el púlpito, desde el confesionario y desde todos los espacios posibles, oportuna e inoportunamente? ¿Cuál era su profesión u oficio? ¿A qué dedicó su vida? ¿A qué información tuvo acceso para pensar en forma diametralmente opuesta a la mayoría?

La respuesta a todas estas preguntas es un enigma mayor, que abre nuevos interrogantes. Contesta todo, explica (y complica) todo. Francisco Gutiérrez era, en realidad, el padre Francisco, presbítero. A partir de su experiencia como sacerdote, llegó a la conclusión inversa a los demás: la mejor forma de expresar el amor a Dios era, justamente, mediante el amor a los pobres. Por eso, la inversión más inteligente para salvar su alma del purgatorio era, justamente, entregar todo por los pobres y no por los rituales sagrados. Para el padre Francisco, valía más ayudar a un ser humano, que repetir ceremonias religiosas, ubicándose su accionar en una concepción

40 Testamento de Francisco Gutiérrez, Santiago de Chile, 21 de diciembre de 1589. AN, FES, volumen 5, folio 86.

41 De lo que se trata es de constituir un "capital espiritual" que, administrado por la Iglesia, sirva a las necesidades en vida y muerte de los comerciantes indianos. LAVRIN, Asunción. Cofradías novohispanas: economías material y espiritual. In: MARTíNEZ LÓPEZ-CANO, María del Pilar, et al. Cofradías, capellanías y obras pías en América Colonial, p.49-64. 
simbolista y escatológica medieval, en la que se consideraba que con las riquezas se podía y debía antes que procurarse de las cosas gratas de este mundo, conseguir de Dios - en la parte y en el momento adecuado - los méritos inherentes a la pobreza ya que no se es pobre, y acerca de los cuales los pobres gozaban ya en la tierra.

\section{Ayuda al pobre fuera del hospital}

Las donaciones a personas pobres, fuera del Hospital, fueron casos especiales. La inmensa mayoría de las donaciones a los pobres se canalizaban a través de limosnas hospitalarias, pero en algunos casos se entregaban también algunos bienes a través de otros canales, ya en forma personal a sujetos específicos, ya por vías institucionales alternas.

La entrega de bienes a personas concretas, como agradecimiento por los servicios prestados en forma personal al testador, fue una práctica relativamente habitual en la América española. Ello se reflejó en algunos testamentos de Santiago de Chile. Por ejemplo, el padre Cristóbal Zamudio y Arbildo (1639) señaló lo siguiente: "declaro por mis bienes una tabla de manteles adamascados y otros llanos nuevo lo cual dará don Diego Zapata a una buena señora pobre que me ha cosido y remendado". ${ }^{42}$ Diez días después, en un nuevo testamento, el padre Cristóbal reiteró su voluntad de donar ese mantel a la costurera, añadiendo unas sábanas. ${ }^{43}$ Otro caso interesante fue el de María Duran (1639). En su testamento dispuso donar ropa a Antonia Fernández "por ser pobre y tenerle amor". El documento fue concebido en los siguientes términos:

Yten mando por que fue voluntad de la dicha difunta que se den a Antonia Fernández mujer de Agustín de Contreras, una ropa de bayeta de Castilla negra traída y un jubón de tafetán de México negro traído y una saya de silicio y un jubón de lo propio traído lo cual mando se le dé por ser pobre y tenerle amor y así mando por la dicha difunta se le dé. ${ }^{44}$

Varios detalles interesante se detectan en este documento. Por un lado, toda la ropa que se dona se caracteriza por estar "traída", es decir, usada. No se le entregaba dinero ni otros bienes, sino ropa usada. La testadora poseía dinero, pero sus prioridades no eran los pobres, sino su propia alma. Ese fue el centro de su interés y el objetivo de sus bienes; para las misas y acompañamientos sacerdotales de su funeral destinó \$159; además, fundó

42 Testamento: Cristóbal de Zamudio y Arbildo, Santiago de Chile, 18 de abril de 1639, folio 327. AN, Notarios de Santiago, volumen 183, folio 237.

43 Testamento: Cristóbal de Zamudio y Arbildo, Santiago de Chile, 28 de abril de 1639. AN, Notarios de Santiago, volumen 184 , folio 5 .

44 Testamento: María Durán, Santiago, 18 de marzo de 1639. AN, Notarios de Santiago, volumen 183, folio 259. 
una capellanía con un capital principal de $\$ 700$, y una renta anual de $\$ 35$, destinado al convento de San Agustín.

La ayuda a personas pobres derivó en otros canales, como muestra el caso de doña Isabel Núñez de Herrera. Miembro del grupo de elite de los conquistadores españoles, doña Isabel disponía de grandes capitales para la época. Al redactar su testamento, resolvió dedicar una parte importante para ayudar a los pobres, priorizando dos grupos principales: los indios de su encomienda y las huérfanas de la cofradía de la Inmaculada Concepción. Para los indios destinó $\$ 400$, de los cuales, la mitad se les daría en ganados y alimentos, y la otra mitad (\$200) se debía invertir a censo en la cofradía de la Inmaculada Concepción para celebrar misas por las ánimas de esos indios. ${ }^{45}$ De este modo la cofradía se beneficiaba de los recursos económicos surgidos del amor de la testadora por los indios de Villarrica. Además de este ingreso, la cofradía recibió otros aportes, incluyendo $\$ 40$ en forma directa, y $\$ 1500$ para misas por la salud de su alma y para socorrer a las huérfanas pobres. Doña Isabel constituyó un mecanismo para asegurar una renta permanente con ese objetivo, concebido en los siguientes términos:

Yten mando que mis albaceas den y entreguen al mayordomo de la Cofradía de la Inmaculada Concepción de Nuestra Señora \$1500 de oro y todo el remanente que quedare de todos mis bienes derechos e acciones para que lo echen en renta sobre buenas posesiones libres y desembarazadas, y la renta de todo ello se gaste y distribuya en esta manera: el cuarto se distribuya en casar huérfanas pobres que sean virtuosas; otra cuarta parte lo haya y goce la dicha cofradía para ayuda a sus necesidades y las otras dos partes se gasten y distribuyan en hacerme decir las misas aquí anotadas en el Monasterio del Señor San Francisco. ${ }^{46}$

Se creaba así una renta, equivalente a una capellanía, por la cual se destinaba una parte (25\%) a socorrer huérfanas pobres y virtuosas con el mejoramiento de sus dotes. Con este mecanismo, la testadora esperaba mejorar la inserción social de esas doncellas, a la vez que fortalecía la autoridad del poder religioso, el cual sería el encargado de definir cuál huérfana pobre era la suficientemente virtuosa como para merecer la donación y mejorar sus condiciones de vida.

\section{Valoración positiva del pobre}

Mientras en el mundo protestante del norte de Europa, la riqueza se consideraba manifestación del amor de Dios, ${ }^{47}$ en el mundo católico de los

45 Testamento de Isabel Núñez de Herrera, Santiago, 10 de mayo de 1590. AN, Escribanos de Santiago, volumen 5, folio 206v.

46 Testamento de Isabel Núñez de Herrera, Santiago, 10 de mayo de 1590. AN, Escribanos de Santiago, volumen 5, folio 207v-208.

47 LIS, Catharina; SOLY, Hugo. Pobreza y capitalismo en la Europa preindustrial. Madrid: Akal, 1984. LITTLE, Lester K. Pobreza voluntaria y economía de beneficio en la Europa Medieval. Madrid: Taurus, 1980. 
reinos españoles de la península Ibérica y de las Indias Occidentales, la situación valorada era la pobreza. ${ }^{48}$ Los pobres eran considerados personas especiales, dignas de recibir ayuda; el pobre daba la oportunidad de practicar la virtud teologal de la caridad. Por tal motivo, cuando se pretendía pedir un trato especial, basado en el amor, se usaba la expresión "tratarlo como a pobre". Este lenguaje se reflejó en los testamentos chilenos de fines del siglo XVI. El caso de Luisa Ortiz de Susunaga (1591) es un buen ejemplo.

Casada con Lorenzo Ginovés, ella tuvo oportunidad de criar tres niños: Antonio, Magdalena y Ángela. El primero era hijo legítimo, la segunda hija natural de su marido, y la última, una arrimada que se crio en la casa. De acuerdo a las leyes españolas, el único heredero legítimo de los bienes del matrimonio era Antonio Ortiz. En cambio las dos niñas, al tener el estigma de ser "hijas del pecado", debían ser obligatoriamente desheredadas. No tenían ningún derecho a recibir bienes de los padres en calidad de herencia. Pero el amor de madre impulsó a Luisa a buscar la forma de favorecer a las niñas después de su muerte. Por un lado, favoreció a Ángela con el ajuar de ropa y el quinto de sus bienes; por otro, otorgó a Magdalena una donación de $\$ 30$ en oro. De todos modos, la testadora consideró que estos aportes eran insuficiente, sobre todo por la edad: Ángela tenía apenas 14 años. Por tal motivo, buscó la forma de integrarlas en familias de su confianza. Y allí es donde aparece el concepto que interesa para el presente estudio. Porque en su afán de asegurar un trato amoroso y delicado para sus niñas, Luisa usó el concepto de "pobre". Concretamente, se apoyó en su albacea, Domingo de Ugarte, y una amiga de su confianza, Antonia de Estrada, para encargarles el cuidado de las dos niñas. La tarea fue encomendada en los siguientes términos: "Al dicho Domingo Ugarte (encargo) haga limosna en llevar a su casa a la dicha Magdalena Ortiz y hacer con ella como con pobre. Asimismo pido y ruego a doña Antonia de Estrada, viuda mujer que fue del licenciado Navia, lleve a sus casas a la dicha Ángela Ortiz y haga con ella como con una pobre". ${ }^{49}$

El texto es un documento valioso porque entrega indicios sobre la forma de pensar en esa cultura. El amor por las niñas Magdalena y Ángela, era lo más valioso en la vida de la señora Luisa. Ninguna de las dos era su hija, pero los dos hijos que ella había dado a luz ya no estaban (una había fallecido y el otro estaba ausente, presuntamente en Lima, sin ningún contacto con la madre). Su marido también había fallecido. Por lo tanto, el centro de su vida emocional estaba focalizado en las dos muchachas. Para Luisa, lo más importante era cuidarlas y asegurarles la mejor vida posible. Por eso,

48 TARIFA FERNÁNDEZ, Adela. Pobreza y asistencia social en la España Moderna: la cofradía de San José y Niños Expósitos de Ubeda (siglos XVII y XVIII). Jaén: Diputación Provincial de Jaén, Instituto de Estudios Giennenses, 1994. LÓPEZ ALONSO, Carmen. La pobreza en la España Medieval.

49 Testamento de Luisa Ortiz de Susunaga. Santiago, 26 de febrero de 1591. AN, FES, volumen 6, folio 186v. 
seleccionó con máximo cuidado las palabras que debía usar para confiarlas a terceros. Y el concepto más adecuado para pedir amor y delicadeza extrema para ellas fue, justamente, "tratarlas como a pobres".

En la sociedad colonial, el pobre estaba revestido de un carácter sagrado. No podía ser maltratado; no había nada para quitarle; no se le podía hacer ningún daño. Merecía respeto, atención y amor. Un pobre no era un par. Era alguien necesitado, que merecía cuidado. Por eso se usaba el concepto en ese sentido, justamente.

Otro elemento que llama la atención es la proyección. La señora Luisa no señala a sus niñas como en una situación de la cual deban salir. No pide a sus futuros tutores que les ayuden a "salir de la pobreza". No era una situación transitoria en la cual se hubiere caído por un problema puntual de la vida, de la cual había que salir con esfuerzo. No: el concepto es diferente. En el documento, la palabra "pobre" quiere decir "que debe ser amado".

\section{Entierros de pobres}

Los altos costos de los funerales, determinados por los derechos que cobraban los eclesiásticos, generó la necesidad de buscar una salida a los pobres. Una opción válida era el entierro en la iglesia del hospital o de su cementerio. Pero hubo cierta tendencia de sectores sociales con recursos, a usar este camino para eludir los gastos funerarios. Por tal motivo, el clero obtuvo del rey Felipe IV, la Real Cédula del 4 de setiembre de 1652, por la cual se disponía que sólo pudiera enterrarse en las iglesias o cementerios de hospitales a los fallecidos dentro del hospital. ${ }^{50} \mathrm{Si}$ el pobre fallecía fuera de ese recinto, se generaba nuevamente una situación complicada que, con frecuencia, se resolvía con entierros clandestinos en sitios no autorizados. Otras opciones eran los entierros en los patios de las parroquias o en cementerios ubicados a extramuros de las ciudades. ${ }^{51}$ Pero en la medida de lo posible, los pobres aspiraban a ser enterrados dentro de las iglesias y conventos de la ciudad.

Como el pobre era merecedor de un trato especial, basado en el amor y la generosidad, se usó también el concepto para solicitar entierros y ceremonias fúnebres sin pagar por sus costos bajo la expresión "de balde", que hacía referencia a la concesión "graciosa" que debían prestar especialmente en estos trámites las cofradías religiosa.

Algunos testadores se proclamaban a sí mismos en la categoría de pobres, y desde esa posición, solicitaban a los albaceas se tuviera en cuenta el criterio para organizar el traslado del cuerpo a la iglesia, las ceremonias fúnebres de sepultura, y la definición del lugar de entierro.

50 LEÓN LEÓN, Marco Antonio. Muerte y buena muerte en Chile colonial, p.201.

51 LEÓN LEÓN, Marco Antonio. Muerte y buena muerte en Chile colonial, p.221-222. 
Por lo general, el traslado del cuerpo del pobre a la iglesia para ser enterrado, se hacía con cruz baja, para diferenciarlo de la cruz alta de los sectores de mayor rango social. Además, había una parte específica para enterrarlos: el arco de los pobres de la Catedral. Algunos testamentos de pobres entregaban estos detalles, otros se limitaban con indicar que debían realizarse las ceremonias propias de pobres. De los 300 testamentos compulsados, en 11 casos se detectaron solicitudes de entierros especiales por ser pobres (Tabla 2).

Tabla 2

Testamentos que solicitan entierros de pobre (Santiago de Chile, 1589-1640)

\begin{tabular}{|c|c|c|}
\hline Testador / año & Oficio y posición & Funerales y entierro \\
\hline Isabel Gálvez (1589) & $\begin{array}{l}\text { Tiene buena ropa y joyas, } \\
\text { pero casi todo empeñado }\end{array}$ & Pide la entierren como pobre. \\
\hline $\begin{array}{c}\text { Francisco Hernández } \\
\text { (1590) }\end{array}$ & $\begin{array}{l}\text { Dice que perdió todos sus } \\
\text { bienes en la guerra de Arauco }\end{array}$ & $\begin{array}{l}\text { "me entierren como a pobre } \\
\text { porque mi necesidad es } \\
\text { grande". }\end{array}$ \\
\hline Úrsula Cam & $\begin{array}{l}\text { Posee un solar con una } \\
\text { casilla }\end{array}$ & $\begin{array}{l}\text { "me entierren como a po- } \\
\text { bre" en monasterio de San } \\
\text { Francisco. }\end{array}$ \\
\hline Juana Valenc & \begin{tabular}{|l} 
Posee joyas y bienes raíces, \\
pero se declara pobre
\end{tabular} & Pide cruz alta. \\
\hline $\begin{array}{r}\text { Magdalena } \\
(163\end{array}$ & $\begin{array}{l}\text { "soy muy pobre" (esposa de } \\
\text { un carpintero) }\end{array}$ & $\begin{array}{l}\text { Cruz baja } \\
\text { de los pol }\end{array}$ \\
\hline Cristóbal Sierra (1636) & Pulpero portugués; pobre & Pide cruz baja por ser pobre. \\
\hline $\begin{array}{c}\text { Cristóbal de Zamudio y } \\
\text { Arbildo } \\
\text { (1639) }\end{array}$ & $\begin{array}{l}\text { Presbítero próspero; tiene } \\
\text { tierras, viñas, rentas, un } \\
\text { esclavo, } \$ 300 \text { en plata y otros } \\
\text { bienes }\end{array}$ & $\begin{array}{l}\text { Pide cruz alta y doble de } \\
\text { campanas, } 1 \text { misa cantada, } \\
63 \text { misas rezadas; entierro en } \\
\text { el lugar que se entierran los } \\
\text { sacerdotes pobres. }\end{array}$ \\
\hline Leonor Valca & descono & $\begin{array}{l}\text { Pide la entierren con pero no } \\
\text { puede pagar los gastos. }\end{array}$ \\
\hline $\begin{array}{r}\text { Mariana de I } \\
(1639 \\
\end{array}$ & $\begin{array}{l}\text { Buena posición; entregó dote } \\
\text { a sus hijas }\end{array}$ & $\begin{array}{l}\text { Pide que "su entierro sea } \\
\text { como de pobre". }\end{array}$ \\
\hline Nicolás Coco (1640) & $\begin{array}{l}\text { Sastre alemán; tiene un hijo } \\
\text { natural al cual deja } \$ 100 ; \\
\text { heredera: su alma }\end{array}$ & $\begin{array}{l}\text { Pide ser enterrado en el Arco } \\
\text { de los pobres; reserva sus } \\
\text { fondos para misas. }\end{array}$ \\
\hline Francisca de Arais (1640) & $\begin{array}{l}\text { Pobre; solo tiene una caja } \\
\text { y una cuja; no tiene ni para } \\
\text { misa de cuerpo presente }\end{array}$ & $\begin{array}{l}\text { Pide cruz baja y ceremonia } \\
\text { de limosna, porque no puede } \\
\text { pagar nada por ser pobre. }\end{array}$ \\
\hline
\end{tabular}

Fuente: Archivo Nacional, Fondo Escribanos de Santiago, 1585-1641.

Dentro de estos once casos, se distinguen dos grupos. Por un lado, tenemos los testadores que efectivamente carecían de bienes. Es el caso de Francisco Hernández, Magdalena de la Serna, Cristóbal Sierra, Leonor Valcázar y Francisca de Arais, que eran realmente pobres y no tenían bie- 
nes para cubrir los gastos de funeral y entierro. Por ese motivo, apelaban al amor de los demás (sobre todo los albaceas y el sector eclesiástico, propietario de los bienes funerarios y rituales) para acceder a servicios que de otra manera, no podrían conseguir. Ellos representaban casi la mitad de los casos y asociaban pobreza real con caridad.

Muy diferente era la situación de la otra mitad de los testadores: seis casos de testadores admitían poseer bienes muebles o inmuebles, y aun así solicitaban entierros de pobres. En varios de estos casos había una inconsistencia notable entre la condición real del testador, y el argumento invocado para obtener servicios sin pagar por ellos: algunos son vecinos con bienes raíces y hasta con joyas de oro y perlas, que se autoproclaman en calidad de "pobres". Esta paradoja no deja de llamar la atención, y nos lleva a profundizar el análisis de esos testamentos.

\section{Pobreza e irresponsabilidad}

La categoría de "pobre" se usó también como mecanismo para asumir una posición de irresponsabilidad. En algunos casos, los vecinos del Reino de Chile se encasillaban dentro de esta calidad, para de esa manera considerarse a sí mismo con la dispensa para no hacerse cargo de sus responsabilidades. Por otra parte, esa situación de "pobreza" no implicaba ausencia de bienes. En algunos casos, el declarante que se autoproclamaba "pobre", poseía bienes raíces y hasta joyas. Pero al ubicarse en la categoría de pobre, quedaba como eximido de hacerse cargo de sus obligaciones normales. La pobreza podía funcionar como un fuero, un privilegio, que permitía al sujeto desentenderse o ser exceptuado de sus obligaciones. ${ }^{52}$ Era una suerte de puerta abierta a la irresponsabilidad.

Uno de los primeros testimonios corresponde a Francisco Hernández de Estrada. Al redactar su testamento (1590) se mencionan una serie de hechos de su vida, entre ellos, se afirma que perdió sus bienes en las guerras del rey. Por tal motivo, quedó en la pobreza. En otra parte, el testador reconoció una serie de deudas, entre ellas, una contraído con Andrés Fernández por \$50. Pidió pagarla a sus familiares "y si no lo hiciere, pido por amor de Dios al dicho Andrés Fernández me lo perdone porque soy pobre"..$^{53}$ Al parecer, se trataba de un detalle menor, dado que la cifra era pequeña. Pero lo interesante en este caso es el antecedente. El testador no argumentaba como justificación que había sacrificado su hacienda en las guerras de Arauco,

52 Por ejemplo, en el virreinato de Nueva España a mediados del siglo XVIII, el "beneficio de pobreza" fue esgrimido por los estudiantes de algunas Universidades Indianas Novohispanas como una estrategia para ascender socialmente desde los estudios secundarios. ABADIE-AICARDI, Aníbal. Contexto socio-cultural de la condición de pobreza y el beneficio de pobreza en la Universidad de México (1553 - 1700).

53 Testamento de Francisco Hernández de Estrada, Santiago, 17 de marzo de 1591. AN, FES, volumen VI, folio 209. 
sino en su condición de pobre. Este era considerado el argumento legítimo para justificar el cierre de las cuentas.

El padre Cristóbal de Zamudio y Arbildo fue otro ejemplo de la invocación de la pobreza para actuar con irresponsabilidad. Gozaba de una posición privilegiada en la sociedad de la época: poseía solar y viña, un esclavo, \$300 en plata labrada, disponía de rentas por administración de bienes de difuntos en calidad de albacea, tarea en la cual se apropió de bienes ajenos y dilató durante décadas la entrega de los mismos a sus herederos. En el ejercicio de su ministerio, asumió la responsabilidad de ceder algunos bienes a personas necesitadas, entre ellas, un muchacho pobre al cual benefició con una pequeña parcela. Sin embargo, pasó el tiempo, y el padre Cristóbal nunca concretó la transferencia. Trató de justificarse al redactar su testamento, alegando pobreza. En efecto, el testador se declaró propietario de:

\begin{abstract}
34 varas de tierra de las del padrón que lindan con viña de Vicente Carrión que tengo los títulos en mi poder y con chácara de don Juan de Inostrosa de la cual tierra hice donación cuando hubo en este ciudad la alfombrilla a un mancebo que ayudé a criar llamado Cristóbal Luis Mogollón. Declaro no haberla podido hacer por mi pobreza y deudas y así la revoco. Así mismo hice otra donación a una niña huérfana ahijada mía del pedazo de casa que está conjunta y dividida a la que hice donación a doña Isabel de Arbildo. Declaro no haberle podido hacer por lo dicho (por mi pobreza y deudas) y la revoco y mando se venda por mis bienes lo uno y lo otro. ${ }^{54}$
\end{abstract}

Invocando su supuesta "pobreza", el sacerdote declaró nulas las dos donaciones. A pesar de no haber sido capaz de honrar esos compromisos, el padre Cristóbal sí logró reunir fondos para financiar el bienestar de su alma en el purgatorio: dispuso que su funeral se realizara con cruz alta, doble de campanas, una misa cantada de cuerpo presente, doce misas rezadas por sacerdotes pobres que debían acompañar su cuerpo con sobrepellices, y otras 52 misas rezadas, a ocho reales cada una. Evidentemente, el sacerdote estaba decidido a realizar una inversión en su futuro personal y disponía de fondos para ello. Pero también era importante para él mostrarse como pobre. Por tal motivo pidió ser enterrado "en la parte y lugar que se entierran los sacerdotes pobres y mi cuerpo vaya amortajado con el hábito de Señor San Francisco que sea el más viejo de un pobre lego a quien se darán diez patacones de limosna considerando mi pobreza y devoción". ${ }^{55}$

Los conceptos de "pobre" y "pobreza" aparecen recurrentemente en este testamento: cuatro menciones a cada uno; en total, ocho veces se menciona explícitamente esta noción, a lo cual habría que añadir las

54 Testamento del presbítero Cristóbal de Zamudio y Arbildo, Santiago, 8 de abril de 1639. AN, FES, volumen 183, folio 327.

55 Testamento del presbítero Cristóbal de Zamudio y Arbildo, Santiago, 8 de abril de 1639. AN, FES, volumen 183, folio 324 . 
alusiones tácitas. Los pobres y la pobreza eran un tema importante para el padre Cristóbal; trataba de manifestarse sensible a esa realidad, e integrarse a la misma. Al parecer, era muy importante para el padre Cristóbal dejar muy claro que era pobre, que lo enterraran en el lugar de los pobres, y lo acompañaran sacerdotes pobres. De esa manera, su imagen quedaba asociada al desprendimiento y se hacía merecedora de la bendición de Dios y de los hombres. Era una forma de penitencia, de purificación por los abusos que había realizado durante su vida. La pobreza funcionaba como un traje, un velo protector, que permitiría reparar y limpiar los abusos. Era como un espacio desde donde se obtenía un crédito que permitía no tener que pagar las cuentas.

Criterios parecidos adoptó el marino Gaspar Sánchez. Piloto del Mar del Sur, desempeñaba el oficio sirviendo las rutas de El Callao a Valdivia, tocando puertos intermedios como Arequipa, Arica y, sobre todo, Valparaíso. Construyó redes sociales y comerciales con vecinos de estas ciudades y de Lima, donde tuvo una hija natural, Luisa Sánchez, a la cual decidió dejar en herencia la suma de \$250. El marino expresó su deseo de cederle esa cantidad, condicionando la donación a una serie de actos previos; en caso de no cumplirse las condiciones, sólo le dejaría una cifra menor; y para justificarse, alegó, justamente, que estaba en situación de pobreza. Así lo señaló en una parte de su testamento:

Tengo en la ciudad de Los Reyes una hija natural la cual se llama Luisa Sánchez la cual es casada y posa en casa del doctor Roca y de su hermana doña Andrea que residen en la ciudad de los Reyes. Mando que se le den hasta \$250 los cuales haya y cobre del pleito que traigo sobre los azogues con Juan Pérez, de las cuentas y compañía que arriba se hace mención ("Compañía de los Azogues"). Y no saliendo con el dicho pleito atento que estoy pobre mando se le den de mi hacienda $\$ 100$ de plata corriente de a nueve reales el peso. ${ }^{56}$

El marino tenía una contradicción interna. Por un lado, sentía que tenía un deber paternal de protección hacia su hija; por eso, expresaba su voluntad de entregarle \$250. Pero también necesitaba dinero para otros objetivos. En primer lugar, para proteger su propia alma de los tormentos del purgatorio: por ello ordenó financiar una misa cantada de cuerpo presente, 40 misas rezadas a los mercedarios y 10 a los franciscanos y dominicos. Además, deseaba pagar deudas a su esposa (todavía no le había dado los $\$ 600$ comprometidos por arras), entre otros gastos. Al parecer, sus recursos no alcanzaban para financiar todo. Por esta razón, trató de optimizarlos, prometiendo más de lo que podía cumplir; y para justificar esta inconsistencia, no encontró mejor argumento que argumentar "estoy pobre". 
Algo parecido hace doña Juana Valenciana, propietaria de una casa con medio solar, una imagen de la Virgen de oro valuada en $\$ 40$, sarcillos de oro, varias gargantillas con perlas y cruces de oro, y también acreedora de una suma importante entregada al capitán Asencio de Zabala. A pesar de disponer de estos bienes, doña Juana se hallaba en una situación complicada; por tal motivo, para sostener sus gastos, debió empeñar varias de sus joyas. Al parecer, la vigencia de los valores de la deshonra legal del trabajo, impuestas por la cultura española de la época, la inhibía de la posibilidad de trabajar para sustentarse. Por tal motivo, no tuvo más remedio que entregar gradualmente sus bienes para financiarse. Poco a poco fue ingresando en la situación llamada de "pobreza solemne". Desde esta posición, no fue capaz de cobrar a sus deudores, y para justificar su actitud, invocó la situación de pobreza en el testamento:

Me debe el alférez Juan Pérez de Aguayo 800 patacones que le presté en Reales a tiempo de 8 años poco más o menos. Mando se cobren y para en cuenta de ellos me ha dado 12 patacones en recaudo en la tienda de Juan Bautista de Orozco. Y esta dicha cantidad traía al trato con que ayudaba mis necesidades y el dicho Juan Pérez de Aguayo no me ha dado nada. Encárgole la conciencia sobre esto porque soy pobre..$^{57}$

Igual que doña Juana, la señora Beatriz Méndez era propietaria en Santiago de Chile, lo cual no obstaba para declararse pobre. En efecto, entre los bienes raíces había tres solares ubicados dentro de la traza de la ciudad. Su voluntad era utilizar esas propiedades para entregárselas a su hijo, hija y para pagar deudas. No deseaba emplear el capital para financiar gastos funerarios. Pero necesitaba organizar su último viaje y su entierro, y para solucionar el problema, señaló: "mando que si Dios nuestro señor fuere servido de me llevar de esta presente vida que mi cuerpo sea enterrado en el monasterio de Santo Domingo de esta ciudad y se me diga el día de mi entierro algunas misas rezadas atento que soy pobre". ${ }^{58}$

Con este procedimiento, Beatriz Méndez se sumaba a la tendencia indicada por el padre Cristóbal de Zamudio, el piloto Gaspar Sánchez y doña Juana Valenciana: se ubicaban como "pobres" para, desde esa posición, solicitar el privilegio de eximirse de asumir las tareas, acciones y responsabilidades de los demás.

\section{¿Qué hacer con los pobres?}

En el marco de la cultura hispanocriolla instalada en el Reino de Chile, cabe hacerse esta pregunta. Para los grupos dirigentes del patriciado

57 Testamento de doña Juana Valenciana, Santiago de Chile, s/f (circa 1600). AN, FES, volumen: 177-a, foja 149v. 58 Testamento de Beatriz Méndez, Santiago, 2 de febrero de 1590. AN, FES, volumen5, folio 102. 
hispano, ¿cuál era el camino más adecuado para tratar a los pobres? Naturalmente, no hay una respuesta lineal ni simple; pero los documentos compulsados entregan algunos indicios, y al parecer, las respuestas eran distintas según el género: para las mujeres se buscaban algunos medios y otros distintos para los varones. La misma Luisa Ortiz señala el criterio que adoptó al respecto: "mando a Magdalena Ortiz hija natural de Lorenzo Ginovés mi marido por el servicio que me ha hecho y me hace, \$30 de oro los cuales mando que mis albaceas se los den en cosas que ella quisiere a su gusto para vestirse". ${ }^{59}$

Como se ha señalado, su hijastra Magdalena Ortiz era una niña pobre, y debía ser tratada con extrema delicadeza. La señora Luisa disponía de \$30 para la niña y debía usarse de la mejor manera para paliar su situación; y el camino más adecuado era comprar ropa. No pensó en algún medio de producción o herramienta de trabajo, sino en vestidos, es decir, en la construcción de una imagen.

En una situación análoga se encontró Cristóbal de Sierra, pulpero de origen portugués, radicado en Santiago, y pobre. Su caso era parcialmente parecido al de Luisa Ortiz, pero con una diferencia importante: igual que ella, tenía que cuidar a un niño que quedaría en la pobreza y debía ayudarlo a paliar la situación; pero había una diferencia: su vástago era un varón y no una mujer. Y la actitud del padre fue diametralmente distinta: al depositar su hijo en personas cercanas, no les encargó atenderlo "como a pobre" ni dispuso invertir recursos en ropa, sino en conocimientos: "Pido y suplico por amor de Dios con lágrimas de mis ojos al dicho alférez Manuel Barbossa que a mi hijo Sebastián de Sierra le haga enseñar a leer y escribir pues es cristiano y le ponga a oficio para que sea hombre. Que Dios le pagara este bien y yo se lo ruego como dicho es". 60

Estos documentos muestran una tendencia importante en el periodo fundacional de la cultura hispanoamericana chilena. La pobreza era un problema complejo que generaba diversas respuestas de la población, y que se agravaba para las mujeres. Los varones recibían conocimientos; se les enseñaba a leer y escribir y a dominar un oficio para ganarse la vida; en cambio, a las mujeres se les entregaba ropas para cuidar la imagen; se les vedaba el acceso al capital cultural para abrirse camino por su propio esfuerzo.

La sociedad hispanocriolla no tenía muy claro qué hacer con los pobres. El discurso de la religión católica, única aceptada en la región, exhortaba decididamente a construir una sociedad inclusiva y solidaria con el pobre. Sin embargo, la interpretación que los clérigos hicieron de las enseñanzas cristianas, fue diametralmente opuesta. La Iglesia aprovechó el control de

59 Testamento de Luisa Ortiz de Susunaga. Santiago, 26 de febrero de 1591. AN, FES, volumen6, Folio 185v.

60 Testamento de Cristóbal de Sierra, Santiago, 24 de julio de 1636. AN, FES, volumen 177b, folio 112v. 
la ideología (a través del púlpito, de la administración de los sacramentos, de las catequesis y la prédica religiosa) para transmitir un criterio muy particular conforme al cual, para merecer el amor de Dios, era mejor invertir los excedentes en misas y otros rituales, antes que en ayudar a los pobres. La acción de propaganda de esta forma de entender la fe, resultó notable.

Muy pocos lograron sustraerse a la ideología dominante. La única excepción, dentro de los trescientos casos estudiados, fue el del clérigo Francisco Gutiérrez. A pesar de haberse educado y vivir dentro del ámbito religioso, fue el único vecino de Santiago que consideró éticamente superior la solidaridad con los pobres (a través del hospital), antes que destinar los recursos a misas y ritos.

Es posible que otros vecinos de Santiago hayan experimentado una tendencia parecida a expresar solidaridad humana con los pobres. Pero en todos los demás casos, esa tendencia fue eficazmente neutralizada por la persistente acción ideológica y "pastoral" del clero. Los sacerdotes lograron convencer a la población de la existencia del purgatorio, y de los tormentos infernales que allí esperaban a todas las almas (salvo a los santos). Las imágenes de las postrimerías, con los dolores insoportables que esperaban a todos en el purgatorio, fueron el artefacto ideológico clave, que logró un efecto extraordinario: deshumanizar a las personas, romper su tendencia a solidarizarse con los necesitados, e "invertir" sus excedentes en ritos con poderes mágicos, capaces de hacerlos salir antes de los tormentos del purgatorio. De esta manera, la ideología construyó un desvío de la ruta del capital que, en vez de dirigirse a la inversión o a la integración social, se transfirió masivamente hacia los conventos y monasterios.

Junto con la opulencia del sector eclesiástico, este mecanismo aseguró la perpetuación de la pobreza y la baja inversión en salud pública. Chile nació con una cultura avara en el campo de la salud pública, lo cual se hizo visible en el Hospital de los pobres. Como la corriente principal era absorbida por otros fines, lo que quedaba para el hospital era un exiguo hilo de agua, que apenas alcanzaba para brindar precarios servicios.

A la acción absorbente de la Iglesia, se sumaron otros problemas. Por un lado, la deshonra legal del trabajo, por la cual, las familias de buena posición social sólo podían ejercer tareas decentes, y no oficios viles; no podían trabajar con sus manos para salir de la pobreza. Este fue un freno cultural que los inhibía para surgir; la cultura dominante tendía a priorizar la imagen, la ostentación de joyas y ropas caras, a la vez que desdeñaba los oficios mecánicos y la cultura del trabajo. A ello se sumaba la discriminación de género, que concedía ventajas a los varones, a los cuales se les podía transmitir conocimientos y oficios; pero perjudicaba a las mujeres, que muchas veces quedaban excluidas del capital cultural necesario para avanzar en el proceso de emancipación material y mental. 
La combinación de estos tres elementos, contribuyó a un proceso de perpetuación de la pobreza en la región. Se perdió la capacidad de percibirla como una situación transitoria de la cual se podía salir a partir del esfuerzo y el trabajo. Se perdió la capacidad de lucha. Incluso, algunos llegaron a encontrar en ella un espacio de justificación para actitudes irresponsables. En algunos casos, estos mecanismos se usaron en detrimento de personas realmente pobres y necesitadas. De esta manera se fue construyendo una cultura de la irresponsabilidad, lo cual se sumó a los elementos anteriores (deshonra legal del trabajo, discriminación de la mujer y abuso de poder por parte del clero) para modelar un sistema sociocultural que tendía a frustrar el desarrollo y a perpetuar la pobreza y las fuertes jerarquías sociales. 